\title{
Tamoxifen enhances the differentiation-inducing and growth-inhibitory effects of all-trans retinoic acid in acute promyelocytic leukemia cells
}

\author{
KOJI ADACHI, YOSHIO HONMA, TAKAAKI MIYAKE, KOSHI KAWAKAMI, \\ TSUTOMU TAKAHASHI and JUNJI SUZUMIYA
}

Department of Oncology/Hematology, School of Medicine, Shimane University, Izumo, Shimane 693-8501, Japan

Received October 27, 2015; Accepted December 4, 2015

DOI: $10.3892 /$ ijo.2016.3348

\begin{abstract}
All-trans retinoic acid (ATRA) is valuable in differentiation therapy for acute promyelocytic leukemia (APL). However, ATRA has had limited success as a single agent, due to the development of resistance. We found that tamoxifen effectively enhanced the differentiation-inducing effect of ATRA. Tamoxifen alone inhibited the proliferation of myeloid leukemia cell lines while only slightly increasing morphologic differentiation. Tamoxifen effectively enhanced the growthinhibiting actions of various differentiation-inducing agents. ATRA in the presence of tamoxifen increased NBT reduction and the expression of CD11b in HL-60 cells more effectively than ATRA alone. Tamoxifen also enhanced the differentiation induced by the other inducers tested. ATRA induced the differentiation of APL cell lines NB4 and HT93 and APL cells in primary culture, and this differentiation was also enhanced by tamoxifen. Tamoxifen is one of the most widely used drugs for the treatment of cancer and has few side effects. The combination of ATRA and tamoxifen might be considered for the treatment of APL patients in whom it can be difficult to apply arsenic trioxide or anthracyclines.
\end{abstract}

\section{Introduction}

All-trans retinoic acid (ATRA) induces a dramatic response in the treatment of patients with acute promyelocytic leukemia (APL), leading to complete remission, but most patients will eventually experience a relapse. The combination of ATRA and anthracyclines results in an overall remission rate of up to $95 \%$ and a cure rate that now exceeds $80 \%$ (1-4). A recent study revealed that the combination of ATRA and arsenic

Correspondence to: Professor Yoshio Honma, Department of Oncology/Hematology, School of Medicine, Shimane University, Izumo, Shimane 693-8501, Japan

E-mail: biohonma@med.shimane-u.ac.jp

Key words: acute promyelocytic leukemia cells, differentiation, growth inhibition, tamoxifen, all-trans retinoic acid trioxide may be superior to the combination of ATRA and chemotherapy for the treatment of patients with low-to-intermediate-risk APL (5). However, hematologic toxicity (acute cytopenia with the resulting infections) was observed in the ATRA/anthracycline group and liver toxicity and long Q-T syndrome were observed in patients in the the ATRA/arsenic trioxide group. Since anthracyclines and arsenic compounds are genotoxic and carcinogenic (6), long-term treatment with these drugs should be avoided as much as possible. Although recent therapy against APL has a high cure rate, further improvements are needed.

To identify a compound that would be useful for APL therapy when combined with ATRA, we have screened various compounds that are less toxic and clinically available, such as inhibitors of signal transduction pathways and physiologically active molecules. As a result, the most effective agent we identified was tamoxifen. We found that tamoxifen effectively enhances the differentiation-inducing and growth-inhibitory effects of ATRA in APL cells. Tamoxifen is a selective estrogen receptor modulator that is used as the first-line treatment for estrogen receptor-positive breast cancer. However, multiple non-estrogen receptor-mediated mechanisms have been implicated in the antitumor effects induced by tamoxifen in estrogen receptor-negative tumors (7). There seems to be a consistent relationship between higher doses of tamoxifen and longer survival in patients with largely inoperable and recurrent malignant glioma (8). Therefore, in the present study, we sought to clarify the combined effects of ATRA and tamoxifen on the growth and differentiation of human myeloid leukemia cells including APL cells.

\section{Materials and methods}

Materials. RPMI-1640 medium, nitroblue tetrazolium (NBT), ATRA, tamoxifen and $\alpha$-tocopherol were purchased from Sigma-Aldrich Co. (St. Louis, MO, USA). Dimethyl sulfoxide (DMSO), 1 $\alpha, 25$-dihydroxy vitamin $\mathrm{D}_{3}$ (VD3), and sodium butyrate were purchased from Wako Chemicals (Osaka, Japan). Fluorescein isothiocyanate (FITC)-labeled anti-CD11b antibody was obtained from Becton-Dickinson Immunocytometry Systems (San Jose, CA, USA). BMS195614 was purchased from Tocris Bioscience, R\&D System Co. (Minneapolis, MN, 
USA). PD98059 was obtained from Calbiochem (La Jolla, CA, USA).

Leukemia patient. Leukemic bone marrow specimen was collected at diagnosis, after the patient gave his written informed consent for sample collection in accordance with institutional policy. A 45-year-old Japanese male was admitted to our hospital, presenting with purpura. Laboratory data on admission were WBC $8,720 / \mu 1$, blasts $63.5 \%$, and platelets $15,000 / \mu 1$. Bone marrow aspiration revealed hyperplastic marrow cells (nucleated cell count $1,232,000 / \mu 1$ ), $94.4 \%$ of which were blasts. APL was diagnosed on the basis of bone marrow morphology and the standard cytogenetic translocation, $\mathrm{t}(15 ; 17)$, in $97 \%$ of cells by FISH analysis.

Cells and cell culture. The HL-60 cell line, derived from an AML patient, and NB4 and HT93 promyelocytic leukemia cells were maintained in RPMI-1640 medium supplemented with $10 \%$ fetal bovine serum and $80 \mu \mathrm{g} / \mathrm{ml}$ gentamicin at $37^{\circ} \mathrm{C}$ in a humidified atmosphere of $5 \% \mathrm{CO}_{2}$ in air (9).

Heparinized bone marrow aspirations were diluted with RPMI-1640 medium supplemented with $10 \%$ fetal bovine serum, overlaid on $15 \mathrm{ml}$ of Ficoll-Paque Plus (Amersham Biosciences, Uppsala, Sweden) and centrifuged at $500 \mathrm{x} \mathrm{g}$ for $30 \mathrm{~min}$. Only specimens that contained $\geq 80 \%$ leukemia cells were studied. The mononuclear cells were washed twice and suspended in RPMI-1640 medium supplemented with $10 \%$ fetal bovine serum, plated in culture dishes at $5-12 \times 10^{5}$ cells $/ \mathrm{ml}$, and incubated at $37^{\circ} \mathrm{C}$ in a humidified atmosphere of $5 \% \mathrm{CO}_{2}$ in air.

Assay of cell growth and properties of differentiated cells. Suspensions of cells $\left(5 \times 10^{4}\right.$ cells $\left./ \mathrm{ml}\right)$ in $2 \mathrm{ml}$ of culture medium were incubated with or without the test compounds in multidishes. Cell numbers were counted in a Model Z1 Coulter Counter (Beckman Coulter, Tokyo, Japan). Superoxidegenerating oxidase was determined by the ability of the cells to reduce NBT upon exposure to $12-O$-tetradecanoyl phorbol13-acetate (9). Cells were incubated in $1 \mathrm{ml}$ of RPMI-1640 medium containing NBT $(1 \mathrm{mg} / \mathrm{ml})$ and $12-O$-tetradecanoyl phorbol-13-acetate $(100 \mathrm{ng} / \mathrm{ml})$ at $37^{\circ} \mathrm{C}$ for $50 \mathrm{~min}$. The reaction was stopped by the addition of $5 \mathrm{M} \mathrm{HCl}(1 \mathrm{M}$, final concentration). The suspension was kept at room temperature for $20 \mathrm{~min}$ and then centrifuged. Formazan deposits were solubilized in dimethyl sulfoxide, and the absorption of the formazan solution at $560 \mathrm{~nm} / 10^{7}$ cells was measured in a spectrophotometer. Morphological changes were examined in cell smears stained with May-Grünwald-Giemsa solution. Surface expression of CD11b was determined by monoclonal antibody labeling and flow cytometry using a FACScan (Becton-Dickinson, Mountain View, CA, USA), as described previously (10).

Colony-forming assay. NB4 cells ( $3 \times 10^{3}$ per dish) were plated into $3 \mathrm{ml}$ of a semisolid medium with $0.8 \%$ methylcellulose and $20 \%$ fetal bovine serum in triplicate multiwell plates (6 wells, $9.6 \mathrm{~cm}^{2}$ growth area/well) for 8 days. A solution of $0.1 \mathrm{ml}$ of PBS containing various concentrations of drugs was added to the semisolid medium. Colonies were photographed under an inverted microscope. Colonies in enlarged photographs were measured and those $>0.4 \mathrm{~mm}$ in diameter were counted.
Bone marrow plugs from a single femur of three Balb/c mice were pooled in RPMI-1640 medium. A single-cell suspension was prepared by vigorous pipetting. Nucleated cells ( 1,000 cells $/ \mathrm{ml} / \mathrm{dish})$ were placed in $1 \mathrm{ml}$ of a semi-solid medium containing haematopoietic growth factors (MethoCult ${ }^{\circledR}$ GF M3434, Stem Cell Technology Inc., Vancouver, BC, Canada) in a 24-well plate and incubated for 8 days (11).

Western blot analysis. Cells were packed after being washed with cold PBS, and then lysed at $1.5 \times 10^{7}$ cells $/ \mathrm{ml}$ in sample buffer [63 mM Tris-HCl (pH 6.8), $15 \%$ glycerol, $2 \%$ sodium dodecyl sulfate (SDS), 5\% 2-mercaptoethanol and $0.005 \%$ bromophenol blue]. The resultant lysates were resolved on $10 \%$ SDS-polyacrylamide gels. The proteins were transferred electrically from the gel to an Immobilon-P membrane (Millipore, Bedford, MA, USA) and immunoblotted with antibody. All antibodies were purchased from Cell Signaling Technology Japan (Tokyo). Horseradish peroxidase (HRP)conjugated antibody (Cell Signaling Technology, CA, USA) was used as a secondary antibody (1:2,000 dilution). The bands were developed by treatment with the Immun-Star HRP Chemiluminescent kit (Bio-Rad Laboratories, Danvers, MA, USA) for $5 \mathrm{~min}$ at room temperature, and detected using a Fuji Lumino Image Analyzer LAS-4000 system (Fuji Film, Tokyo, Japan).

Statistical analysis. The results are expressed as means \pm standard deviation (SD). Pairs of data were compared using Student's t-test. Significant differences were considered to exist for probabilities $<5 \%(\mathrm{P}<0.05)$.

\section{Results}

Effects of tamoxifen on the differentiation and growth of myeloid leukemia cells. Various compounds induce human myeloid leukemia HL-60 cells to undergo differentiation into granulocytes and monocytes (12). We examined the effects of tamoxifen on the differentiation and growth of HL-60 cells. Tamoxifen concentration-dependently inhibited the proliferation of HL-60 cells and induced the expression of CD11b, a surface marker of myelomonocytic differentiation (Fig. 1A). Since our previous report indicated that $\alpha$-tocopherol prevents the growth-inhibitory effect of tamoxifen in pancreatic cancer cells (11), we examined the effect of $\alpha$-tocopherol on CD11b expression in HL-60 cells (Fig. 1A). $\alpha$-tocopherol significantly suppressed tamoxifen-induced CD11b expression, but had little effect on ATRA-induced CD11b expression. Tamoxifen also induced the reduction of NBT, a functional marker of differentiation (Fig. 1B). However, tamoxifen scarcely affected morphologic changes (Fig. 1C). These results indicate that tamoxifen is not a potent inducer of differentiation. Tamoxifen effectively enhanced the growth-inhibitory and NBT-reducing effects of VD3 in HL-60 cells (Fig. 1B). Tamoxifen also enhanced the morphologic differentiation of HL-60 cells induced by VD3 (Fig. 1C). Next, we examined the effects of tamoxifen on the growth-inhibitory and NBT-reducing effects of ATRA, butyrate, and DMSO (Fig. 2). Tamoxifen enhanced ATRA-induced NBT reduction in the APL cell line NB4 (Fig. 3A). Although ATRA significantly inhibited the proliferation of HT93 cells, viable cells were still observed among 

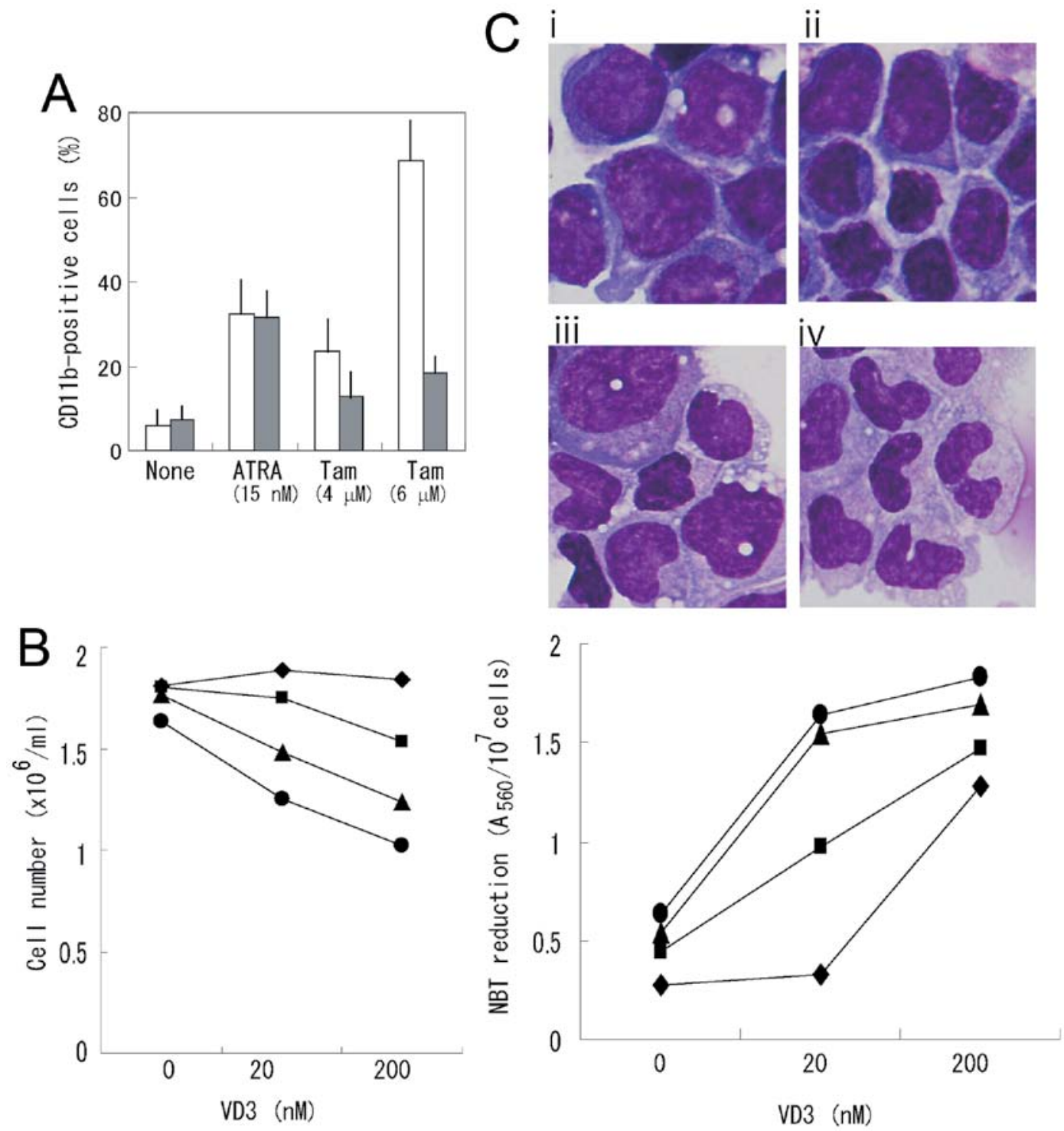

Figure 1. (A) Induction of CD11b expression in HL-60 cells by tamoxifen in the presence or absence of $\alpha$-tocopherol. HL-60 cells were cultured with tamoxifen (Tam) or ATRA in the presence (gray square) or absence (white square) of $200 \mu \mathrm{M} \alpha$-tocopherol for 4 days. Means \pm SD of three determinations. (B) Growthinhibitory (left panel) and NBT-reducing (right panel) effects of tamoxifen in HL-60 cells in the presence of VD3. HL-60 cells were cultured with 0, 2, and $200 \mathrm{nM}$ VD3 in the presence of 0 (black rhombus), $1 \mu \mathrm{M}$ (black square), $2 \mu \mathrm{M}$ (black trinagle), and $3 \mu \mathrm{M}$ (black circle) tamoxifen for 4 days. (C) Morphological differentiation of HL-60 cells treated with VD3 and/or tamoxifen (original magnification x1,000). Cells were cultured with $2 \mu \mathrm{M}$ tamoxifen (ii), 20 nM VD3 (iii), or $2 \mu \mathrm{M}$ tamoxifen plus $20 \mathrm{nM}$ VD3 (iv) for 6 days. (i) Untreated control.

HT93 cells treated with $900 \mathrm{nM}$ ATRA, as judged by the MTT assay (Fig. 3B). Tamoxifen and ATRA co-operatively inhibited the viability of HT93 cells, and no viable cells were observed in a culture with a combination of $6 \mu \mathrm{M}$ tamoxifen and $900 \mathrm{nM}$ ATRA for 6 days.

The growth-inhibitory effect of tamoxifen on NB4 cells was prevented by treatment with $\alpha$-tocopherol, even in the presence of ATRA (Fig. 3C). ATRA-induced inhibition of the growth of NB4 cells was concentration-dependently counteracted by a selective antagonist of retinoic acid receptor- $\alpha$, BMS195614, while this antagonist hardly affected the growthinhibitory effect of tamoxifen (Fig. 3D).

Role of ERK activation in the combined effects of ATRA and tamoxifen. Several inducers including ATRA activate ERK in leukemia cells before inducing myelomonocytic differentia- tion, and this activation is needed to elicit differentiation and growth arrest $(13,14)$. Treatment with PD98059, a specific inhibitor of MAPK kinase (MEK) phosphorylation and activation (15), resulted in a loss of ERK activity from leukemia cells and blockade of the differentiation of leukemia cells (16). ATRA significantly increased ERK activity and this increased ERK activity was reduced by pretreatment with PD98059 (13). This inhibitor also suppressed the NBT reduction induced by ATRA, suggesting that ERK activation is required for ATRA-induced differentiation (13). PD98059 also inhibited tamoxifen-induced NBT reduction in HL-60 cells (Fig. 3E), and kinase activity was enhanced in tamoxifen-treated cells (Fig. 3F). Fig. 3E shows that treatment with PD98059 reduced the NBT reduction induced by ATRA plus tamoxifen. These results suggest that synergism between ATRA and tamoxifen in the inhibition of proliferation and induction of differentia- 

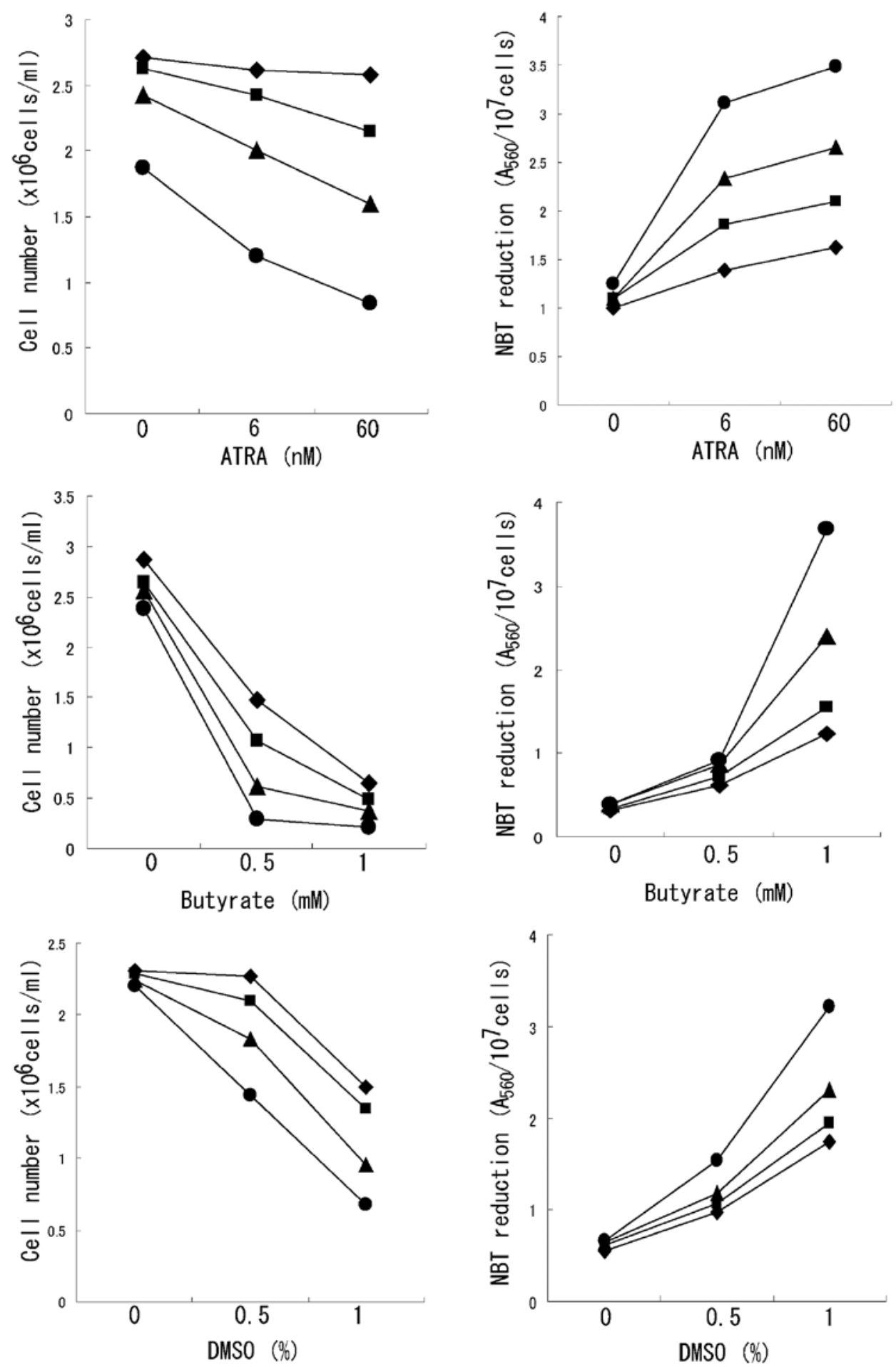

Figure 2. Growth-inhibitory (left panel) and NBT-reducing (right panel) effects of tamoxifen in HL-60 cells treated with various differentiation inducers. Cells were cultured with ATRA, sodium butyrate, or dimethyl sulfoxide (DMSO) in the presence of 0 (black rhombus), $2 \mu \mathrm{M}$ (black square), $4 \mu \mathrm{M}$ (black trinagle), or $6 \mu \mathrm{M}$ (black circle) tamoxifen for 6 days.

tion of myeloid leukemia cells is, at least in part, due to ERK activation by tamoxifen.

Combined effects of tamoxifen and ATRA on colony formation by NB4 cells and normal mouse bone marrow cells. A colony-forming assay indicated that, while ATRA effectively inhibited the formation of large colonies, $30 \mathrm{nM}$ ATRA could not completely eliminate small colonies (Fig. 4). The mean colony numbers in untreated and ATRA-, tamoxifen-, and ATRA plus tamoxifen-treated cultures were $476.5 \pm 51.6$, $218.1 \pm 23.2,132.3 \pm 22.6$, and $0.6 \pm 0.1$ ( $\pm \mathrm{SD}$ ), respectively. Combined treatment with ATRA and tamoxifen completely suppressed colony formation by NB4 cells, although several clusters $(<0.1 \mathrm{~mm}$ in diameter) were observed in cultures treated with this combination (Fig. 4D), suggesting that the combined treatment was not cytotoxic. Next, the combined 

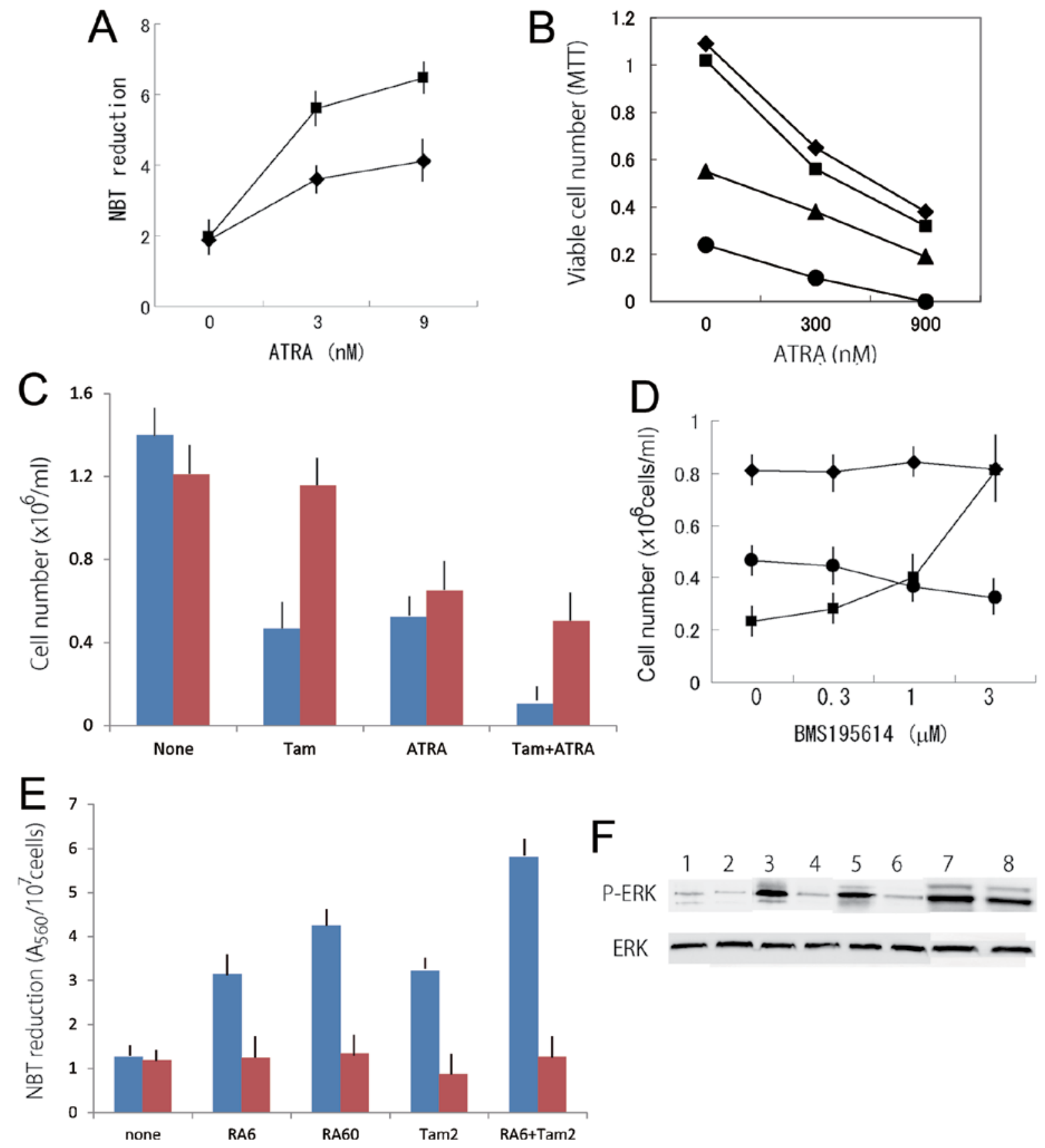

Figure 3. (A) Combined effects of ATRA and tamoxifen on NBT reduction in NB4 cells. Cells were cultured with (black square) or without (black rhombus) $2 \mu \mathrm{M}$ tamoxifen in the presence of ATRA for 4 days. Means of four determinations. (B) Combined effects of ATRA and tamoxifen on the proliferation of HT93 cells. Cells were cultured with 0 (black rhombus), $2 \mu \mathrm{M}$ (black square), $4 \mu \mathrm{M}$ (black trinagle), or $6 \mu \mathrm{M}$ (black circle) tamoxifen in the presence of ATRA for 4 days. Viable cell numbers were determined by the MTT assay. Means of four determinations. (C) Effect of $\alpha$-tocopherol on the proliferation of NB4 cells treated with tamoxifen and/or ATRA. Cells were cultured with (red square) or without (blue square) $200 \mu \mathrm{M} \alpha$-tocopherol in the presence or absence of $8 \mu \mathrm{M}$ tamoxifen (Tam) or $30 \mathrm{nM}$ ATRA (ATRA) for 4 days. Means \pm SD of three determinations. (D) Effect of BMS195614 on the proliferation of NB4 cells treated with tamoxifen or ATRA. Cells were cultured with $4 \mu \mathrm{M}$ tamoxifen (black circle) or $6 \mathrm{nM}$ ATRA (black square) for 4 days. Black rhombus, untreated control. Means \pm SD of three determinations. (E) Effect of PD98059 on NBT reduction in HL-60 cells treated with ATRA and/or tamoxifen. Cells were cultured with (red square) or without (blue square) $1 \mu \mathrm{M}$ PD98059 in the presence of $6 \mathrm{nM}$ ATRA (RA6), $60 \mathrm{nM}$ ATRA (RA60), $2 \mu \mathrm{M}$ tamoxifen (Tam2) or $6 \mathrm{nM}$ ATRA plus $2 \mu \mathrm{M}$ tamoxifen (RA6+Tam2) for 4 days. Means \pm SD of three determinations. (F) Effect of PD98059 on the induction of ERK activity in HL-60 cells treated with ATRA and/or tamoxifen. Cells were cultured without $(1,3,5$, and 7$)$ or with $1 \mu \mathrm{M}$ PD98059 $(2,4,6$, and 8$)$ in the absence (1 and 2$)$ or presence of $4 \mu \mathrm{M}$ tamoxifen ( 3 and 4), $30 \mathrm{nM}$ ATRA (5 and 6) or $4 \mu \mathrm{M}$ tamoxifen plus $30 \mathrm{nM}$ ATRA ( 7 and 8 ) for 2 days.

effects of ATRA and tamoxifen on colony formation in mouse bone marrow cells were compared to those in NB4 cells. The combination of $30 \mathrm{nM}$ ATRA plus $6 \mu \mathrm{M}$ tamoxifen significantly suppressed colony formation by NB4 cells but hardly affected colony formation by normal mouse bone marrow cells.
Both the number of colonies and the colony size in the treated cultures were similar to those in untreated cultures (Fig. 4E and F). These results suggest that APL cells were more sensitive to combined treatment with ATRA and tamoxifen than normal hematopoietic cells. 

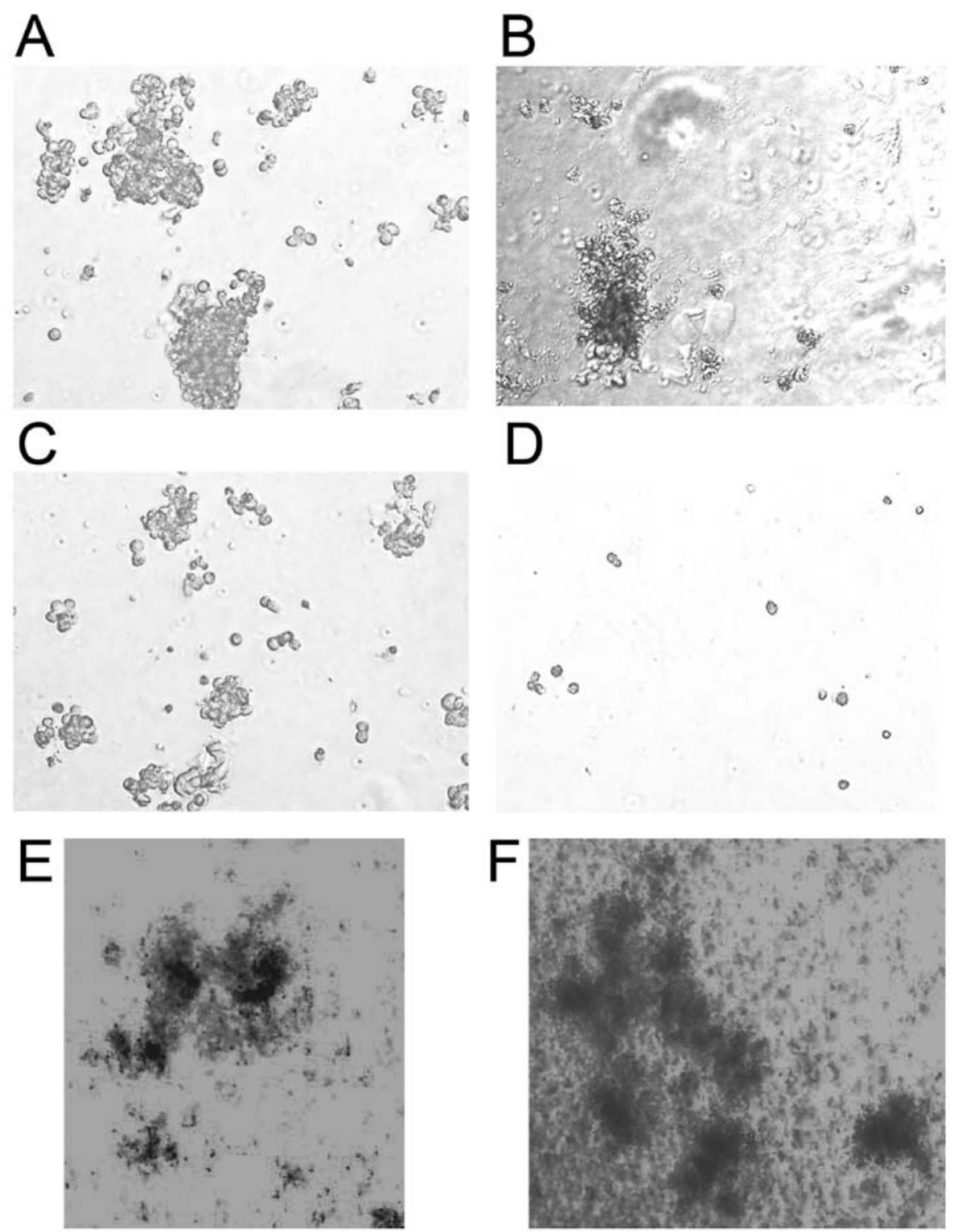

Figure 4. Colony formation by NB4 cells and normal mouse bone marrow cells treated with ATRA and/or tamoxifen. NB4 cells were cultured without (A) or with $30 \mathrm{nM}$ ATRA (B), $6 \mu \mathrm{M}$ tamoxifen (C) or $30 \mathrm{nM}$ ATRA plus $6 \mu \mathrm{M}$ tamoxifen (D) for 8 days. Colony formation by mouse bone marrow cells in the absence (E) or presence (F) of $30 \mathrm{nM}$ ATRA plus $6 \mu \mathrm{M}$ tamoxifen for 8 days.

Combined effects of ATRA and tamoxifen on cell viability and differentiation of APL cells in primary culture. APL cells were freshly isolated and incubated with various concentrations of ATRA and tamoxifen for 3 days. We analyzed morphological changes in APL cells in primary culture. Most untreated APL cells were still blastic after 3 days of culture (Fig. 5A). Tamoxifen did not affect the morphological changes in APL cells (Fig. 5B). Although ATRA at $300 \mathrm{nM}$ induced APL cells to differentiate into myelocytes and metamyelocytes, $9 \mathrm{nM}$ ATRA did not significantly affect the morphology of APL cells (Fig. 5C). Combined treatment with $9 \mathrm{nM}$ ATRA and $2 \mu \mathrm{M}$ tamoxifen significantly induced the granulocytic differentiation of APL cells (Fig. 5D), suggesting that tamoxifen enhances the granulocytic differentiation of APL cells induced by ATRA.

Under treatment with ATRA for 3 days, although malignant cells did not grow, most of the cells were still viable even at a high concentration $(300 \mathrm{nM})$. In the presence of $6 \mu \mathrm{M}$ tamoxifen, ATRA concentration-dependently reduced the numbers of viable cells (Fig. 5E).

\section{Discussion}

Tamoxifen has been extensively tested and is widely used. It is inexpensive and has a low side-effect profile, and thus represents a very attractive therapeutic option. The growthinhibitory activity of tamoxifen in human APL cells seems to be estrogen receptor-independent. $17 \beta$-estradiol did not affect the growth and differentiation of leukemia cells treated with or without ATRA. An antagonist specific to retinoic acid receptor- $\alpha$ did not affect the growth-inhibitory effect of tamoxifen. On the contrary, $\alpha$-tocopherol, a membrane stabilizer, effectively counteracted the effects of tamoxifen on leukemia cells. Tamoxifen elevated lipid peroxidation and 


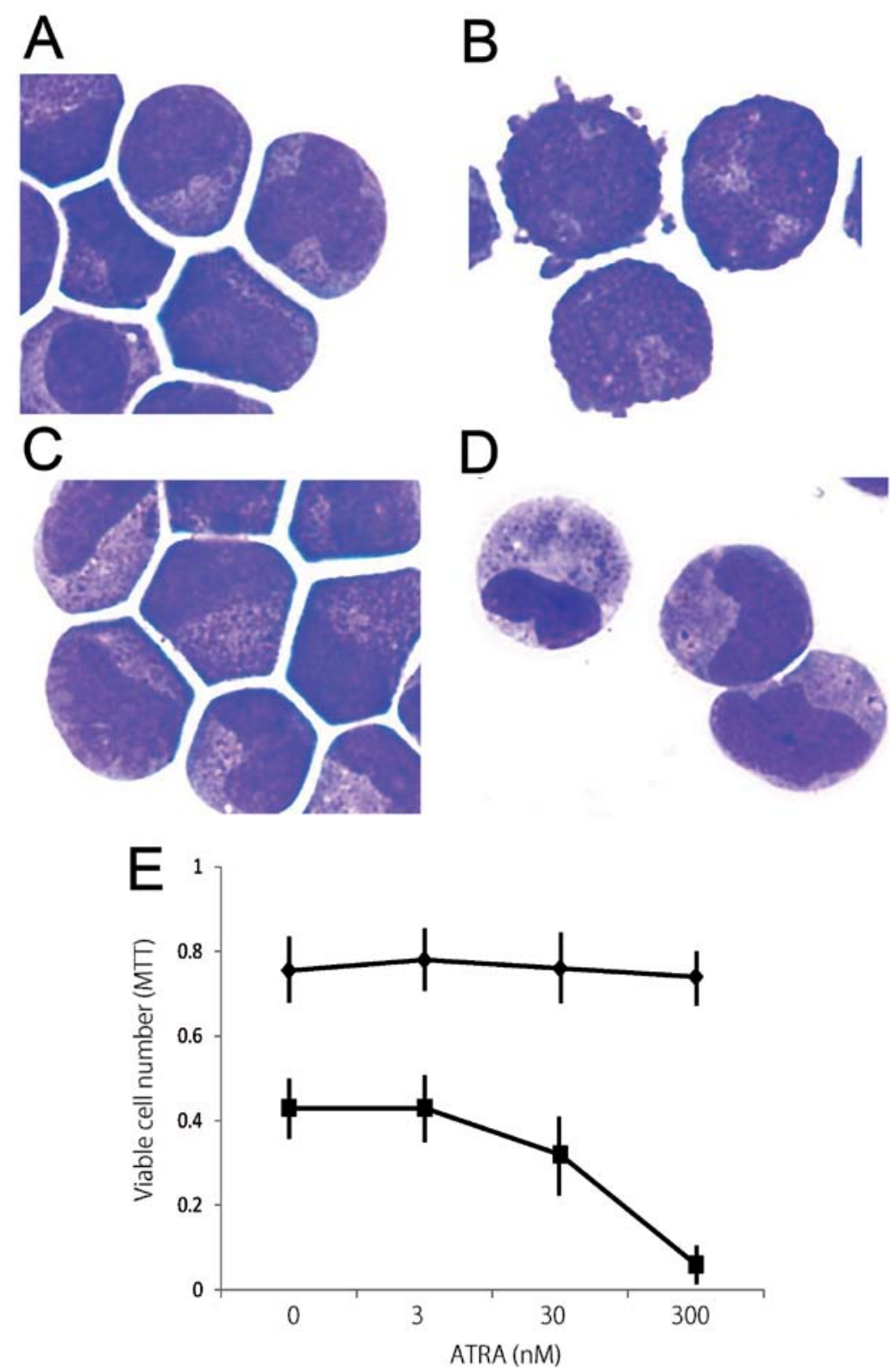

Figure 5. Combined effects of ATRA and tamoxifen on morphologic changes and cell viability of APL cells in primary culture. APL cells were cultured without (A) or with $2 \mu \mathrm{M}$ tamoxifen (B), $9 \mathrm{nM}$ ATRA (C) or $2 \mu \mathrm{M}$ tamoxifen plus $9 \mathrm{nM}$ ATRA (D) for 3 days. (E) Combined effects of ATRA and tamoxifen on cell viability of APL cells in primary culture. APL cells were cultured with various concentrations of ATRA in the presence (black square) or absence (black rhombus) of $6 \mu \mathrm{M}$ tamoxifen for 3 days. Cell viability was determined by the MTT assay. Means \pm SD of four determinations.

induced membrane damage via a mitochondria-dependent pathway $(11,17)$. However, we cannot exclude the possibility that unique estrogen receptor(s) might be involved in the action of tamoxifen. Kauss et al reported that HL-60 cells expressed a membrane receptor for estrogen that modulated ATRA-induced cell differentiation (18).

Although tamoxifen does not have potent differentiationinducing and growth-inhibitory effects in APL cells, it effectively enhanced the effects of ATRA on APL cells. This combined treatment did not significantly affect colony formation by normal mouse bone marrow cells, suggesting that some system helps normal cells recover from membrane damage induced by tamoxifen. This difference between normal and leukemia cells may contribute to a scheme for modulating lipid peroxidation in the membrane as a strategy to selectively kill leukemia cells.
Several inducers such as ATRA and VD3 activate ERK in leukemia cells before inducing myelomonocytic differentiation, and this activation is needed to elicit differentiation and growth arrest $(13,14)$. Tamoxifen also activated ERK in leukemia cells, and combined treatment with ATRA and tamoxifen further enhanced the phosphorylation of ERK. These results suggest that tamoxifen induces membrane damage via lipid peroxidation and then causes the activation of ERK signaling.

A phase I trial of tamoxifen with daunorubicin has been performed in patients with relapsed or refractory acute leukemia (19). Plasma levels of tamoxifen approached $7 \mu \mathrm{M}$ in patients treated with high-dose tamoxifen $(550$ or $700 \mathrm{mg} /$ day, p.o., for 7 days). No severe hepatic, cardiac or retinal toxicity was noted. The toxicity of the combination of tamoxifen and daunorubicin was comparable to that seen with daunorubicin 
alone. This study suggested that plasma concentrations of tamoxifen that are high enough to enhance the differentiation and growth arrest of APL cells can be approached with an acceptable toxicity profile. The combination of ATRA and tamoxifen should be considered for the treatment of APL patients in whom it is difficult to apply arsenic trioxide or anthracyclines.

\section{References}

1. Wang ZY and Chen Z: Acute promyelocytic leukemia: From highly fatal to highly curable. Blood 111: 2505-2515, 2008.

2. Tallman MS, Andersen JW, Schiffer CA, Appelbaum FR, Feusner JH, Woods WG, Ogden A, Weinstein H, Shepherd L, Willman C, et al: All-trans retinoic acid in acute promyelocytic leukemia: Long-term outcome and prognostic factor analysis from the North American Intergroup protocol. Blood 100: 4298-4302, 2002.

3. Asou N, Kishimoto Y, Kiyoi H, Okada M, Kawai Y, Tsuzuki M, Horikawa K, Matsuda M, Shinagawa K, Kobayashi T, et al; Japan Adult Leukemia Study Group: A randomized study with or without intensified maintenance chemotherapy in patients with acute promyelocytic leukemia who have become negative for PML-RARalpha transcript after consolidation therapy: The Japan Adult Leukemia Study Group (JALSG) APL97 study. Blood 110: 59-66, 2007.

4. Adès L, Guerci A, Raffoux E, Sanz M, Chevallier P, Lapusan S, Recher C, Thomas X, Rayon C, Castaigne S, et al; European APL Group: Very long-term outcome of acute promyelocytic leukemia after treatment with all-trans retinoic acid and chemotherapy: The European APL Group experience. Blood 115: 1690-1696, 2010.

5. Lo-Coco F, Avvisati G, Vignetti M, Thiede C, Orlando SM, Iacobelli S, Ferrara F, Fazi P, Cicconi L, Di Bona E, et al; Gruppo Italiano Malattie Ematologiche dell'Adulto; GermanAustrian Acute Myeloid Leukemia Study Group; Study Alliance Leukemia: Retinoic acid and arsenic trioxide for acute promyelocytic leukemia. N Engl J Med 369: 111-121, 2013.

6. Ratnaike RN: Acute and chronic arsenic toxicity. Postgrad Med J 79: 391-396, 2003.

7. Mandlekar S and Kong ANT: Mechanisms of tamoxifen-induced apoptosis. Apoptosis 6: 469-477, 2001.

8. Avgeropoulos NG and Batchelor TT: New treatment strategies for malignant gliomas. Oncologist 4: 209-224, 1999.
9. Niitsu N, Ishii Y, Matsuda A and Honma Y: Induction of differentiation of acute promyelocytic leukemia cells by a cytidine deaminase-resistant analogue of 1- $\beta$-D-arabinofuranosylcytosine, 1-(2-deoxy-2-methylene- $\beta$-D-erythro-pentofuranosyl)cytidine. Cancer Res 61: 178-185, 2001.

10. Takahashi T, Kawakami K, Mishima S, Akimoto M, Takenaga K, Suzumiya J and Honma Y: Cyclopamine induces eosinophilic differentiation and upregulates CD44 expression in myeloid leukemia cells. Leuk Res 35: 638-645, 2011.

11. Miyake T, Honma Y, Urano T, Kato N and Suzumiya J: Combined treatment with tamoxifen and a fusicoccin derivative (ISIR-042) to overcome resistance to therapy and to enhance the antitumor activity of 5-fluorouracil and gemcitabine in pancreatic cancer cells. Int J Oncol 47: 315-324, 2015.

12. Honma Y: Cotylenin A - a plant growth regulator as a differentiation-inducing agent against myeloid leukemia. Leuk Lymphoma 43: 1169-1178, 2002

13. Yen A, Roberson MS, Varvayanis S and Lee AT: Retinoic acid induced mitogen-activated protein (MAP)/extracellular signal-regulated kinase (ERK) kinase-dependent MAP kinase activation needed to elicit HL-60 cell differentiation and growth arrest. Cancer Res 58: 3163-3172, 1998.

14. Wang $X$ and Studzinski GP: Activation of extracellular signal-regulated kinases (ERKs) defines the first phase of 1,25-dihydroxyvitamin $\mathrm{D}_{3}$-induced differentiation of HL60 cells. J Cell Biochem 80: 471-482, 2001.

15. Dudley DT, Pang L, Decker SJ, Bridges AJ and Saltiel AR: A synthetic inhibitor of the mitogen-activated protein kinase cascade. Proc Natl Acad Sci USA 92: 7686-7689, 1995.

16. Ishii Y, Kiyota H, Sakai S and Honma Y: Induction of differentiation of human myeloid leukemia cells by jasmonates, plant hormones. Leukemia 18: 1413-1419, 2004.

17. Nazarewicz RR, Zenebe WJ, Parihar A, Larson SK, Alidema E, Choi $\mathrm{J}$ and Ghafourifar P: Tamoxifen induces oxidative stress and mitochondrial apoptosis via stimulating mitochondrial nitric oxide synthase. Cancer Res 67: 1282-1290, 2007.

18. Kauss MA, Reiterer G, Bunaciu RP and Yen A: Human myeloblastic leukemia cells (HL-60) express a membrane receptor for estrogen that signals and modulates retinoic acid-induced cell differentiation. Exp Cell Res 314: 2999-3006, 2008.

19. Berman E, McBride M, Lin S, Menedez-Botet C and Tong W: Phase I trial of high-dose tamoxifen as a modulator of drug resistance in combination with daunorubicin in patients with relapsed or refractory acute leukemia. Leukemia 9: 1631-1637, 1995. 